\title{
O legado de Paulo Leminski e seu lugar na tradição literária brasileira
}

Cláudio José de Almeida Mello Universidade Estadual do Centro-Oeste

Resumo: Atento às possibilidades das linguagens de seu tempo, o autor multifacetado Paulo Leminski reelabora materiais verbais e não verbais de fontes diversas em prol de uma nova expressão, adequada a uma nova visão de mundo. Como mostra a sua própria condição de vida, o autor pagou o preço até de uma sobrevivência difícil por não aderir ao mercado; talvez por isso, ele pôde elaborar sua obra com uma radicalidade estética que o coloca entre os maiores autores da literatura brasileira contemporânea. Mais de 20 anos após sua morte, ainda estamos em débito com ele, cuja produção - que inclui poesia, prosa, música, diálogos interartes, ensaios, traduçôes, biografias -, pela sua qualidade estética, demanda estudos aprofundados que permitam uma difusão à altura de seu lugar na tradição literária brasileira.

Palavras-chave: Paulo Leminski, Literatura brasileira contemporânea, Cânone literário.

1 Agradecimentos à Fundação Araucária do Paraná pela bolsa de produtividade em pesquisa, que permitiu a realização deste trabalho. 


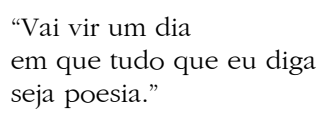

Paulo Leminski (1940-1989) ficou mesmo conhecido como poeta, apesar de suas incursões pela música, como compositor, e de suas traduções, ensaios, biografias e narrativas. Articulado com grandes intelectuais de seu tempo, o autor vivenciou a ascensão do Concretismo, influenciou a sua geração e as posteriores, e permanece, nesses quase 25 anos que já nos separam de sua morte, como um dos mais importantes nomes da literatura brasileira contemporânea, entretanto sem receber o devido tratamento que, como tal, merece, tanto por parte do mercado editorial quanto da crítica literária, e, por consequência, também por parte dos leitores. Com o objetivo de destacar a necessidade da retomada da obra de Leminski, este artigo lembra flashes de sua trajetória, apresenta a bibliografia do autor, e identifica nela aspectos relevantes para reconhecer a sua qualidade estética.

Conforme Mello², com 13 anos de idade Leminski deslocou-se de Curitiba para São Paulo para estudar no Colégio São Bento, um mosteiro beneditino do século XVII, em cuja generosa biblioteca conheceu clássicos como Camões, Antônio Vieira e Homero. Já demonstrando apego à literatura, ajudou a fundar informalmente uma academia de Letras e esboçar uma biografia dos principais santos da Ordem. De volta ao Paraná, ele se interessa pela história antiga e pela literatura latina, grega, francesa e até pelas Sagradas Escrituras, em hebraico. A partir daí, não se afasta das atividades literárias, incluindo leituras de Maiakovski, Walt Whitman, Pound, Poe, e publicando suas primeiras crônicas e poemas em jornais estudantis.

Aos 18 anos, participou da Semana Nacional de Poesia de Vanguarda, na qual conheceu críticos e escritores como Pedro Xisto, Luiz Costa Lima, Boris Schnaiderman, José Lino Grünewald, Décio Pignatari, Haroldo e Augusto de Campos (em cuja casa ficou hospedado na passagem por São Paulo, e com quem passaria a se corresponder). Augusto lembra-se: "Eu fiquei impressionado. Ele era muito novo e tinha um entendimento e uma identificação com o nosso

2 MELLO. A intertextualidade pós-moderna de Agora é que são elas, p. 7. 
trabalho como nenhum outro poeta naqueles anos”³. Em razão desse encontro, Leminski participou da revista Invenção, expoente da vanguarda dos anos 60, e fundou, em sua própria casa, o Núcleo Experimental de Poesia Concreta de Curitiba, criando e também traduzindo nomes como John Donne e Mallarmé.

Os anos que se seguem são de atividades culturais ininterruptas. Começou a escrever o Catatau, o que levaria oito anos, lecionou História, Literatura e Redação em cursinhos pré-vestibulares, tornando-se um dos professores mais disputados da capital paranaense, em razão do sucesso com os alunos, devido ao seu conhecimento enciclopédico e ideias revolucionárias. Foi nessa época que praticou judô - tendo chegado à faixa preta -, quando passou a ter contato com a filosofia zen-budista e com a literatura e língua japonesas. Em 1968 passou a viver com Alice Ruiz, com quem teve Miguel, Áurea e Estrela.

Em busca de um centro maior, teve uma breve estada no Rio de Janeiro, fazendo trabalhos para jornais e revistas, época em que aprendeu a tocar violão de forma autodidata e compôs a primeira de suas várias músicas, posteriormente criadas em parceria com artistas como Moraes Moreira, Itamar Assunção, Jorge Mautner, José Miguel Wisnik e Arnaldo Antunes.

Em Curitiba, após deixar o magistério e a publicidade, continua escrevendo e agitando o meio cultural. Em razão de suas posições radicais, que desafiavam os padrões, e também de seu modo de vida desregrado, vai consolidando sua imagem de poeta maldito.

1975 é o ano de publicação do Catatau, aclamado por críticos e poetas - entre eles os irmãos Campos, Décio, Schnaiderman e Octavio Paz - como uma obra de referência na literatura contemporânea brasileira e latinoamericana. Então Leminski começa a ser conhecido e reconhecido local e nacionalmente. Em 1976 lança Quarenta clics em Curitiba, uma aproximação de fotografia e poesia, em parceria com o fotógrafo Jack Pires. Seu primeiro livro de poesia sai em 1980, Não fosse isso e era menos, não fosse tanto e era quase, uma seleção de sua produção desde 1963. No mesmo ano sai o segundo, Polonaises, dedicado ao professor Boris Schnaiderman.

Em 1981, suas músicas começam a ser reconhecidas por grupos importantes: a banda Blindagem gravou um LP com sete de suas canções, seguida por Paulinho Boca de Cantor, Caetano Veloso, os conjuntos A Cor do

3 VAZ. Paulo Leminski: o bandido que sabia latim, p. 69. 
Som, MPB4 e Os Trovantes (de Portugal), além de Moraes Moreira, com quem fez várias parcerias, dentre elas "Promessas demais", tema de abertura de novela da Rede Globo.

Em 1983, a editora Brasiliense o convida para escrever biografias, e ele lança Cruz e Sousa, que abre as portas da editora para o poeta. Nesse mesmo ano sai Matsuó Bashô e sua primeira tradução, Folhas das folhas de relva, de Walt Whitman. No mesmo ano, publica uma coleção de poemas selecionados de Não fosse isso e era menos, não fosse tanto e era quase, Polonaises e revista Invenção, além de letras de música e os capítulos inéditos "Ideolágrimas", "Solte" e "Contos semióticos". O livro, intitulado Caprichos e relaxos, apresentado por Haroldo de Campos e Caetano Veloso, com circulação nacional e sucesso de vendas - três edições e 18 mil exemplares esgotados em menos de dois anos -, é muito bem recebido por críticos como Leyla Perrone-Moisés e poetas como Régis Bonvicino, que o apontou, "Sem exagero, o melhor livro de poesia do ano"

Em 1984, outra biografia, Jesus A.C., e duas traduções, Pergunte ao pó, de John Fante, e Vida sem fim, de Ferlinghetti. Então, Leminski é convidado a escrever um romance para a coleção Cantadas Literárias, no prazo de seis meses: Agora é que são elas, primeiro livro do escritor mal recebido pela crítica, com algumas exceções. No ano seguinte, ele publica as traduções Supermacho, de Alfred Jarry, Satyricon, de Petrônio, Sol e aço, de Yukio Mishima, e Um atrapalho no trabalbo, de John Lennon.

Em 1986 vem a última tradução, Malone morre, de Samuel Beckett, e a última biografia, Trotsky, a paixão segundo a revolução, além de uma coleção de ensaios produzidos ao longo dos anos, intitulada Anseios crípticos. Em 1987, um dos convites para trabalhar no Rio de Janeiro e São Paulo veio da Funarte, para a série de debates "Os sentidos da paixão", ao lado de José Miguel Wisnik, Sérgio Paulo Rouanet e Marilena Chauí. Publica ainda o livro de poemas Distraidos venceremos.

Em 1988, trabalha na TV Bandeirantes de São Paulo em um programa com o sugestivo nome de Jornal de Vanguarda, onde, segundo um dos diretores, demonstra grande domínio da linguagem audiovisual. ${ }^{5}$ Ainda em 1988, sai Guerra dentro da gente, literatura infantojuvenil. Nessa época, seu estado de saúde era péssimo, em função da cirrose hepática que o consumia e

4 VAZ. Paulo Leminski: o bandido que sabia latim, p. 242.

5 VAZ. Paulo Leminski: o bandido que sabia latim, p. 283. 
o levaria à morte, em sete de junho de 1989, ano em que sai a segunda edição do Catatau e A lua no cinema, literatura infantil (poemas). Depois disso, vêm La vie en close (1991), Metaformose (1994) e O ex-estranho (1996), todos livros de poesia, além de Gozo fabuloso, o mais recente (2004), seu livro de contos e crônicas.

Talvez esse ecletismo nas atividades de Leminski, que inclui publicidade e estudo da filosofia, música e artes marciais, diálogo entre fotografia e poesia, jornalismo e literatura oriental, além de variados gêneros literários, tenha relação com sua produção poética: versos livres, haicais, poemas concretos, em línguas inglesa e francesa além do vernáculo, poemas com e sem humor, erotismo, existencialismo, metapoesia etc.

Diferente de sua primeira narrativa, Catatau, de difícil leitura, na poesia de Leminski há, em geral, um apelo bastante interessante para a formação do leitor, por geralmente propiciar a interação já em um primeiro contato, além de oferecer para o leitor mais atento, em muitos poemas, uma reflexão mais aprofundada da síntese conteúdo-expressão.

Dessa forma, há variados poemas que aparentemente ficam na primeira leitura, como "o p que / no pequeno \& / se esconde / eu sei por q / só não sei / onde nem e"; outros, de um "rimismo gratuito" : "acordei bemol / tudo estava sustenido / sol fazia / só não fazia sentido", ou ainda "a palmeira estremece / palmas para ela / que ela merece" ". Aparentemente porque, considerando a profundidade de outros, vale a pena insistir na leitura de textos mais simples à primeira vista, como o próprio autor escreve: "O papel é curto. / Viver é comprido. Oculto ou ambíguo, / Tudo o que digo / tem ultrasentido". É nessa perspectiva que se pode apontar o poema "Merda e ouro": "Merda é veneno. / No entanto, não há nada / que seja mais bonito / que uma bela cagada. / Cagam ricos, cagam padres / cagam reis e cagam fadas. / Não há merda que se compare / à bosta da pessoa amada” ${ }^{8}$.

Depois do primeiro riso, o leitor poderá perceber no título a dicotomia estabelecida entre o que é condenado e o que é valorizado na sociedade. Em seguida, a exploração do grotesco, que opõe, de acordo com Bakhtin ${ }^{9}$, ao autoritarismo das (pseudo) verdades, concebidas como abstratas,

6 BONVICINO. Envie meu dicionário, p. 226.

7 LEMINSKI. Caprichos e relaxos, p. 32.

8 LEMINSKI. Distraidos venceremos, p. 31.

9 Cf. BAKHTIN. A cultura popular na Idade Média e no Renascimento. 
o lado concreto da vida na relação material do corpo com o cosmos, uma relação que associa vida e morte, de forma ambivalente: já no primeiro verso a excrescência é identificada com o que se ingere, e ainda é "bela". Isso é utilizado para compor o processo de carnavalização, no qual as elites são rebaixadas; note-se que são apenas sujeitos identificados com o poder que "cagam": ricos, padres, reis, os quais, destituídos de sua autoridade pela ação praticada no poema, são equiparados a seres fantasiosos, como as "fadas". Portanto, o primeiro riso provocado pelo poema adquire uma leitura política, a partir de uma análise mais detida.

De outro lado, há numerosos poemas que asseguram a qualidade estética de Leminski, cuja compreensão exige um leitor iniciado. Nesses, uma recorrência importante é a metapoesia, muitas vezes abordando a temática da tradição literária, como em "Plena pausa": "Lugar onde se faz / o que já foi feito, / branco da página, / soma de todos os textos, / foi-se o tempo / quando, escrevendo, / era preciso / uma folha isenta. / Nenhuma página jamais foi limpa. / Mesmo a mais Saara, / ártica, significa. / Nunca houve isso, / uma página em branco. / No fundo, todas gritam, / pálidas de tanto" ". Se no século XIX ("foi-se o tempo") o conceito romântico da originalidade impunha-se como convenção poética para a produção literária, no século XX ele cede espaço para o conceito bakhtiniano de intertextualidade ("nenhuma página jamais foi limpa"). De acordo com Gadamer, ${ }^{11}$ o próprio conhecimento humano é construído pelo diálogo estabelecido no presente entre o intérprete e a tradição, portanto, cada texto remete a todos os anteriores e, assim, não deixa de ser um pouco deles também ("soma de todos os textos"), um "mosaico de citações". de literatura comparada predominava a ideia de fonte e influência ${ }^{13}$, na qual um texto "original" (europeu) projetava a sua força e influência sobre outros, que eram, portanto, compulsoriamente secundários, posteriormente outros críticos literários, sobretudo latinoamericanos, como Borges, utilizam a intertextualidade para ver que o texto segundo não "deve" ao primeiro, uma vez que o texto mais recente pode iluminar no primeiro aspectos antes insuspeitos ("nenhuma página jamais foi limpa"). O que não impede o poeta de fazer uma brincadeira

10 LEMINSKI. Distraídos venceremos, p. 29.

11 Cf. GADAMER. Verdade e método.

12 Cf. KRISTEVA. Semiótica do romance.

13 Cf. THIEGHEM. Crítica literária, história literária, literatura comparada.

14 Cf. BORGES. Kafka y sus precursores. 
com a "angústia da influência", ${ }^{15}$ sentida diante da força do cânone erigido por "poetas fortes": "Bom dia, poetas velhos. / Me deixem na boca / o gosto de versos / mais fortes que não farei. / Dia vai vir que os saiba / tão bem que vos cite / como quem tê-los / um tanto feito também, / acredite" ${ }^{\text {"16 }}$.

Apesar do inexorável diálogo intertextual de cada palavra com a tradição literária, o poeta, ciente de seu ofício, busca a linguagem nova, e tematiza a ruptura com convenções como as de gênero (assim como fizera no Catatau): "sim / eu quis a prosa / essa deusa só diz besteiras / fala das coisas / como se novas / não quis a prosa / apenas a ideia / uma ideia de prosa / um esperma de trova / um gozo / uma gosma / uma poesia porosa" ${ }^{17}$.

Pela leitura apenas dos poemas citados, poder-se-ia pensar que a poesia para Leminski seria apenas um exercício de escrita, mas há outros em que ele manifesta a necessidade da experiência vivida, associada ao rigor do trabalho artesanal com a linguagem: "um bom poema / leva anos / cinco jogando bola, / mais cinco estudando sânscrito, / seis carregando pedra, / nove namorando a vizinha, / sete levando porrada, / quatro andando sozinho, / três mudando de cidade, / dez trocando de assunto, / uma eternidade, eu e você, / caminhando junto" ${ }^{18}$.

Como se nota, há na poesia leminskiana uma coloquialidade permeada quase sempre por uma sensibilidade criativa, não só em poemas com humor, mas também naqueles mais reflexivos, como "contranarciso", em que ele aborda a questão metafísica da alteridade.

Provavelmente devido àquele apelo ao leitor oferecido pela poesia de Leminski, com uma linguagem acessível e ágil, associada à inventividade e ao humor, geralmente em textos curtos, esta é a parte de sua obra mais difundida. Mas a sua prosa merece, sem dúvida, ser mais lida e estudada, devido ao seu valor estético.

Começando pelo Catatau. A obra, recebida em 1975 com interesse pela crítica, ainda hoje é pouco difundida e compreendida. De fato, o "romance-ideia" é de difícil leitura: 213 páginas de texto contínuo, utilizando recursos modernos associados a James Joyce e Guimarães Rosa, como a livre associação de ideias, o fluxo de consciência, a (re)invenção da linguagem, caracterizando uma obra

15 Cf. BLOOM. A angústia da influência.

16 LEMINSKI. Caprichos e relaxos, p. 20.

17 LEMINSKI. Caprichos e relaxos, p. 60.

18 LEMINSKI. La vie en close, p. 9. 
aberta $^{19}$, que possibilita leituras múltiplas e exige uma ativa participação do leitor. Desse modo, este não encontrará aquilo que muitas vezes se espera de uma narrativa: um enredo lógico-causal. Lendo e relendo o romance (e sobre ele), percebe-se que a ação principal não é a que ocorre no plano físico, pois esta se resume a uma espera: Cartesius, recém-chegado da Europa, é atormentado durante toda a narrativa por Occan, um personagem semiótico que opera diabruras no pensamento e na linguagem do narrador, o que o impossibilita de compreender o que se passa no espaço brasileiro do século XVII, motivo pelo qual ele aguarda o polonês Artichewski, na esperança de que este o auxilie.

Conforme Mello ${ }^{20}$, em função do caráter fragmentário da narrativa, as referências históricas existentes no Catatau são imprecisas, relidas pelo tratamento estético que impregna a obra, sob o clima da metamorfose. Ainda assim, fica claro que os três personagens citados remetem a personalidades históricas. A primeira delas diz respeito a René Descartes, filósofo racionalista cujo pensamento estava centrado na busca da verdade, por meio de um método seguro. Concebendo o homem como a criação mais perfeita de Deus, guiado pela sua inteligência racional, o método para a verdade deveria pautar-se por uma lógica baseada na razão. Quanto a Occan, parece haver uma referência histórica bastante direta a Guilherme de Ockham, pensador nominalista cuja tese, contrária às correntes filosóficas em voga na segunda metade da Idade Média europeia, recusava a essência, as ideias gerais, que seriam apenas palavras aplicadas indistintamente a qualquer referente; para o nominalismo, portanto, há uma preponderância dos signos, e o que possibilita o acesso ao conhecimento são os sentidos, em vez da razão, como acontece no cartesianismo. Por último, aquele que remete ao coronel Kristovf d'Artischau Arciszewski, polonês integrante do poderio holandês a serviço da Companhia das Índias no Brasil. ${ }^{21}$ A personagem homônima que remete a ele tem papel importante na paródia do pensamento cartesiano, pois Cartesius o espera durante toda a narrativa, na esperança de que ele o auxilie a compreender o caos em que se encontra. Entretanto, Artychewsky só aparece nas últimas três linhas da narrativa, completamente fora de si: "AUMENTO o telescópio: na subida, lá vem ARTYSCHEWSKY. E como! Sãojoãobatavista! Vem bêbado, Artyschewsky bêbado... Bêbado como polaco

19 Cf. ECO. Obra aberta.

20 MELLO. Discurso social, história e política no romance histórico contemporâneo de lingua portuguesa: Leminski, Lobo Antunes e Pepetela, p. 73.

21 Cf. SALVINO. Catatau: as meditações da incerteza, p. 69. 
que é. Bêbado, quem me comprenderá?",22, assinalando a negação da razão pura por meio do delírio.

Verifica-se uma desconstrução cultural dos valores europeus, insuficientes para compreender a realidade latinoamericana, a qual, incorporada na própria forma da narrativa, resulta na estética neobarroca ${ }^{23}$, que associa a irregularidade, o desvio, a irracionalidade do barroco histórico à questão política da antropofagia do século XX, marcada pelo reconhecimento da dependência econômica simultaneamente com a recusa da dependência cultural em relação ao "velho" Mundo. ${ }^{24}$ O Catatau, portanto, apresenta-se como uma antiliteratura ${ }^{25}$, o que coaduna com a tematização da intertextualidade presente na poesia de Leminski.

Outra narrativa do autor que avaliamos como de qualidade estética, mas que, provavelmente devido à possibilidade de um nível de leitura imediato, tem enganado boa parte da crítica que se debruçou sobre ela, é Agora é que são elas, cuja primeira impressão é de uma obra fácil, divertida, sem maiores pretensões, com muito sexo, orgias, ações sem sentido, que às vezes se anulam, frases soltas, enredo fragmentado, personagem que troca de nome sem explicações, enfim, o caos.

Deixando essa primeira leitura, mergulhamos em um plano teórico mais denso, que dá sustentação à opção estética adotada na obra. Bem distante de um enredo tradicional - com começo, meio e fim -, a narrativa empreende um diálogo sobretudo com a Morfologia do conto, publicada em 1928 por Vladimir Propp. Nesse livro, o teórico traça normas para os contos populares russos, identificando funções das quais os personagens não poderiam escapar. O poeta curitibano desconstrói essa norma, fazendo uma paródia à lógica detectada por Propp nas narrativas folclóricas.

No livro de Leminski, Propp entra como personagem, só que quer usar as funções dos personagens estudadas na Morfologia do conto em um tratamento psiquiátrico para o narrador. Vê-se que a paródia é estendida à psicanálise e, de resto, à cultura ocidental, associada à racionalidade.

Trata-se, no fundo, da problematização da relação do homem com o mundo, evidenciando que o sentido de tudo o que percebemos é histórico, e

22 LEMINSKI. Catatau, p. 213.

23 Cf. SARDUY. O barroco e o neobarroco, p. 161-178.

24 Cf. SANTIAGO. O entre-lugar do discurso latino-americano, p. 11-28.

25 Cf. ALEGRíA. Antiliteratura, p. 243-278. 
não transcendental. Logo, essa lógica com a qual construímos a realidade não é uma Verdade absoluta. Para fazer isso, Agora é que são elas utiliza uma poética transgressora, abundante em erotismo como parte do processo de rebaixamento da ordem dominante por meio da carnavalização - no carnaval, tudo é permitido, não há normas, reina o livre clima de festa popular. ${ }^{26}$ Como se vê, a abundância, no livro, do sexo, da violência, das orgias, tem menos um caráter banal do que um importante papel na desconstrução da ordem instituída.

Ao fazer isso, Agora é que são elas remete a mecanismos de construção presentes tanto no discurso da ficção quanto no discurso da história. Afinal, ambas são narrativas construídas no presente por um narrador, com um necessário diálogo com a tradição. Não é à toa que a narrativa é autorreflexiva, pois chamar a atenção para o próprio processo de elaboração é uma maneira de evidenciar as escolhas sempre ideológicas, afastando-se do caráter pronto das verdades absolutas.

Portanto, o tom paródico do diálogo estabelecido com a história em Agora é que são elas debocha da pretensa seriedade dos textos históricos e da literatura que os inveja, questionando valores atemporais e propondo, em lugar da unidade e do absoluto, a multiplicidade e a disparidade. Onde Vladimir Propp vê estruturas, Paulo Leminski vê convenções, daí problematizar qualquer estrutura, qualquer atribuição de sentido, daí ver a tradição com ironia, entendendo que os signos da história não correspondem aos acontecimentos do mundo.

Talvez seja a incorporação da carnavalização, da paródia e do riso na forma do romance o que leva a algumas leituras ligeiras de Agora é que são elas, pois esses recursos tradicionalmente não são empregados em gêneros "maiores". Entretanto, lembramos que a renovação formal é inerente ao caráter inacabado do romance. Nesses termos, Leminski falou sério quando disse que "Agora é que são elas é uma brincadeira com a mentira de escrever um romance redondo hoje" ${ }^{27}$, só que do ponto de vista genológico.

Como se vê, nos textos "não-poéticos" o tratamento estético das questões apresentadas no plano do conteúdo ressaltam o quanto do poeta Leminski existe em suas narrativas, sobretudo no Catatau. É o que acontece também em Guerra dentro da gente. A obra possui um enredo claro, a história de um menino que acompanha um velho para aprender a arte da guerra. Depois

26 Cf. BAKHTIN. A cultura popular na Idade Média e no Renascimento.

27 GUIMARÃES. Entrevista com Paulo Leminski, p. 6. 
de deixar sua aldeia com um desconhecido, passar por aventuras, enfrentar perigos, aprender muito com a vida, ele, já adulto, regressa ao ponto de partida e reencontra o velho, só que então não mais na condição de aprendiz. O autor constrói essa narrativa de tons lendários com uma linguagem ágil, sem excessos, evidenciando uma autonomia dos personagens, que parecem ter "vida própria", com discursos autônomos, o que pode ser associado àquilo que Bakhtin percebeu nos romances de Dostoiévski: "a multiplicidade de vozes e consciências independentes e imiscíveis e a autêntica polifonia de vozes plenivalentes (...) As personagens se conhecem, intercambiam suas 'verdades', estão de acordo ou em desacordo, dialogam entre si (inclusive no que se refere às questões definitivas da cosmovisão)" ${ }^{28}$. A obra, portanto, afasta-se do modelo monofônico, em que um narrador parece orquestrar as vozes dos personagens. Guerra dentro da gente, ao contrário, denota o trabalho artístico do artefato verbal e não verbal, como se nota na relação autêntica, não meramente ilustrativa, do texto com desenhos, alguns dos quais compostos também com palavras, de forma bastante criativa: literatura infantojuvenil com qualidade estética.

O labor artístico que marca as convenções poéticas encontra-se também nas quatro biografias escritas pelo autor, de Bashô, Jesus, Trótski e Cruz e Sousa, reunidas em 1998 pela Editora Sulina numa coletânea intitulada Vida. O autor não apenas conta as histórias dessas quatro personalidades, como muitas vezes acontece em biografias, num tom monocórdio, linear e progressivo; ele desenvolve a literariedade do gênero biográfico por meio de textos provocativos, mesclados por tópicos, poemas, desenhos, mais com ideias do que com informações objetivas, utilizando a linguagem como um artefato poético.

Esse aspecto aparece também nas cartas do poeta, justamente aí, onde ele certamente fica mais à vontade, já que não estaria produzindo literatura; nota-se que, para ele, linguagem é poesia, e, mesmo quando se dedica a gêneros não necessariamente literários, como o biográfico e o epistolar, ele explora as possibilidades poéticas da linguagem verbal e não verbal, como em sua correspondência com o poeta Régis Bonvicino. ${ }^{29}$

Quanto ao livro mais recente de Leminski, Gozo fabuloso, lançado em 2004 pela DBA Editora, trata-se de uma reunião de contos e crônicas, muitos deles publicados anteriormente em jornais e revistas. São narrativas curtas, com

28 BAKHTIN. Problemas da poética de Dostoiévski, p. 4.

29 Cf. BONVICINO. Envie meu dicionário. 
enredos enxutos, a linguagem precisa; os textos são ecléticos, com humor e coloquialidade, uns com temas sérios, outros nem tanto; há narrativas lúdicas e narrativas históricas (algumas revisitam acontecimentos e personalidades antigos e importantes de Curitiba e do Paraná), uns mais metalinguísticos, outros menos, mas o que se nota em todos os contos da coletânea é mesmo o apego do poeta pelo ato de narrar, como ele próprio escreve no prólogo do livro: "Óbvio o título desta legião de enredos. Gozo fabuloso só pode ser o delírio combinatório de extrair do restrito infinito dos entrechos possíveis uma história sem par, delícia só comparável à de cantar uma canção bonita." ${ }^{30}$ De fato, em muitos dos textos dessa coletânea encontra-se o cuidado artesanal presente no restante da obra do poeta.

Boa parte do que foi apontado neste artigo como aspectos importantes a serem observados na obra literária de Leminski - a síntese conteúdo-expressão, a coloquialidade dita poeticamente, o humor revestido de questões políticas, a linguagem precisa mas revestida de sensibilidade, a postura transgressora diante das formas poéticas consagradas - está presente em $\mathrm{Um}$ escritor na biblioteca e nos Ensaios e anseios crípticos escritos pelo autor, nos quais ele se manifesta com clareza sobre temas da teoria literária incorporados esteticamente em sua obra, como a relação dialógica ou intertextual de cada texto com a tradição literária, associada à busca de nova forma de expressão, característica essencial de toda manifestação artística contemporânea.

Para uma obra tão diversa, que inclui, além dos gêneros citados, ainda a música e a fotografia, com a qual dialogou ${ }^{31}$, fica fácil imaginar que as referências escolhidas pelo autor são plurais. Conforme interessante ensaio de Assunção,

Em Leminski, o foco de interesses não está centrado num cânone rígido e restrito. Sua multiplicidade atrai referências de diversas épocas e culturas: da poesia clássica chinesa ao blues afro-americano, da patafísica de Jarry ao vigor samurai de Yukio Mishima, dos clássicos gregos ao rock'n'roll, do haicai japonês ao tropicalismo, de Cruz e Sousa a Leon Trotsky, de James Joyce a John Fante, de Samuel Beckett a Cartola, de poemas do Egito Antigo ao videotexto, do supraerudito ao supremo popular, do universo cósmico de uma biblioteca aos movimentos mundanos. ${ }^{32}$

30 LEMINSKI. Gozo fabuloso, p. 13.

31 Cf. LEMINSKI; PIRES. Quarenta clics em Curitiba.

32 ASSUNÇÃO. Artilharia ligeira para um kamiquase, p. 1. 
As variadas fontes em que bebeu o autor não significam uma incorporação aleatória, mas sim uma apropriação consciente e criativa de autores, obras, áreas, línguas de origens diversas, o que lhe permitiu converter essas fontes em um caldeirão cultural a partir do qual produziu sua obra, também ela variada, porém com uma característica permanente: a busca de uma relação entre eu e mundo não cooptada pela lógica única, racional-cartesiana, na qual a linguagem está a serviço da representação. Em Leminski ganha evidência a linguagem como artefato essencialmente poético, em sua possibilidade de manifestação da vida, como assinala Assunção:

Disposto a fugir da ilusão "refletora" da arte, seus poemas, conscientemente elaborados, vão se transformando em quase koans. As frases rápidas, carregadas de musicalidade e sentidos se encarregam de dar um nó no pensamento lógico/cartesiano e a escrita vai se tornando uma experiência que compreende cada vez mais uma totalidade corporal. ${ }^{33}$

Tratando de influência, no sentido contemporâneo da palavra como diálogo intertextual, não se pode negar a importância de Leminski para boa parte da geração de ficcionistas e poetas que produziram da década de 1980 para cá, o que denota o lugar especial do autor na tradição literária brasileira, como reconheceu Haroldo de Campos, com faro certeiro:

Das primeiras invencionices ao Catatau, da poesia destabocada e lírica (mas sempre construída, sabida, de fabbro, de fazedor) ao verso verde-verdura da canção trovadoresco-popular, o Leminski vem chovendo no endomingado piquenique sobre a erva em que se converteu a neoacadêmica poesia brasileira de hoje, dividida entre institucionalizadas marginalidades plácidas e escoteiros orfeônicos, de medalhinha e braçadeira. E é bom que chova mesmo, com pedra e pau-a-pique. Evoé Leminski! ${ }^{34}$

Os diálogos com Paulo Leminski, insinuados nas palavras do crítico, podem ser percebidos em poetas como Arnaldo Antunes, Alice Ruiz, Antonio Risério, Régis Bonvicino, contemporâneos de produção, ou em outros que se consagraram depois, como Rodrigo Garcia Lopes e Ademir Assunção, além de tantos outros escritores, músicos, poetas, tradutores, publicitários.

33 ASSUNÇÃO. Artilharia ligeira para um kamiquase, p. 1.

34 CAMPOS. Prólogo. In: LEMINSKI. Caprichos e relaxos, p. 9. 
Apesar do lugar-referência de Leminski na literatura brasileira, boa parte da sua produção permaneceu bom tempo esgotada: em consulta realizada em 2010 a uma das maiores livrarias brasileiras, a Cultura, constatamos que de 20 títulos procurados, 10 estavam indisponíveis, incluindo Agora é que são elas, reeditado em 1999 pela Editora Brasiliense, e Catatau, em 2004, pela Travessa Editores. Quanto à poesia, até o início de 2013 livros publicados em vida por Leminski, como Distraídos venceremos e Caprichos e relaxos, e mesmo o póstumo La vie en close, eram raridades disputadas em sebos, restando ao leitor interessado a coletânea Melhores poemas de Paulo Leminski, que, apesar do benefício de oferecer uma mostra da produção do autor, é um recorte sujeito a ressalvas, sobretudo pelo adjetivo "melhores".

Felizmente, esse panorama tem mudado. Em 2010 a Editora Iluminuras publicou a sua edição do Catatau, e no ano seguinte foi a vez de Agora é que são elas. Em 2013, uma publicação que marca a história de Leminski no mercado editorial: o lançamento da sua trajetória poética completa, pela Companhia das Letras, com uma edição cuidadosa de 424 páginas, apresentação de Alice Ruiz, uma poeta que conhece tão bem o autor, além de uma reunião de textos críticos de, entre outros, Haroldo de Campos, Leyla Perrone-Moisés e José Miguel Wisnik, estudioso da música que aborda aspectos interessantes do Leminski cancionista pouco estudados até agora.

Além disso, segundo Moreira ${ }^{36}$, o acervo pessoal de Leminski foi doado pelas filhas do autor, Estrela Leminski e Áurea Ruiz Leminski, herdeiras do espólio, à PUC-PR, o que deverá permitir uma gama importante de estudos sobre documentos, cartas, anotações, fotos e outros itens do arquivo pessoal do poeta curitibano.

A crítica literária sobre Leminski, entretanto, tem sido tímida em termos quantitativos, majoritariamente composta de trabalhos acadêmicos de mestrado e doutorado. Dentre esses, destaca-se o citado Catatau: as meditações da incerteza, publicação do ano 2000, oriunda de dissertação de mestrado em Comunicação e Semiótica pela PUC-SP, de autoria de Rômulo Valle Salvino, por apresentar uma leitura perspicaz da metamorfose presente no "romance-ideia", mostrando que faz parte da estética da obra uma lógica da contradição, inerente à poética neobarroca, iluminando, assim, a complexa relação entre temáticas

35 Cf. GÓES; MARINS. Melhores poemas de Paulo Leminski.

36 MOREIRA. Espólio de Paulo Leminski: literatura contemporânea? Patrimônio cultural? 
e mecanismos de composição presentes na narrativa de Leminski. Há outros bastante interessantes, alguns deles citados no site mantido pela família do autor (http://fundacaopauloleminski.blogspot.com), uns disponíveis em bancos de teses on line, outros em livros. Mas são poucos, diante da quantidade, qualidade e diversidade da sua produção.

Outro aspecto relevante não só para a difusão de Leminski no exterior, como também para o reconhecimento de sua dimensão na própria literatura brasileira, são as traduções de sua obra, inexistentes até o momento em publicações, justamente ele que exerceu com tanto esmero a arte da tradução.

Apesar dessas lacunas, e diante da reconhecida relevância do autor na tradição literária brasileira, não só devido à qualidade estética de sua obra, como também pela sua apropriação por escritores, poetas, músicos, atores, além de sua consagração entre os leitores, não resta dúvida de que Paulo Leminski é um artista emblemático para compreender o desenvolvimento da literatura brasileira contemporânea.

\title{
Paulo Leminski's legacy and his place in the Brazilian literary
} tradition

\begin{abstract}
Intent to the possibilities of the languages of his time, the multifaceted author Paulo Leminski reworks out verbal and not verbal materials of diverse sources in favour of a new expression, adjusted to a new vision of world. As his proper condition of life shows, the author paid the price even of a difficult survival for not adhering to the market; perhaps therefore, he could elaborate his literary production with an aesthetic radicality that places him among the greatest authors of contemporary Brazilian literature. Today, more than 20 years after his death, we are still in debit with him, whose production - including poetry, prose, music, interart dialogues, essays, translations, biographies -, because its aesthetic quality, demands deepening studies that allow a diffusion up to his place in the Brazilian literary tradition.

Keywords: Paulo Leminski, Contemporary Brazilian literature, Literary canon.
\end{abstract}




$$
\text { Referências }
$$

ALEGRÍA, Fernando. Antiliteratura. In: FERNÁNDEZ MORENO, César (Coord.). América Latina em sua literatura. Trad. Luiz João Gaio. São Paulo: Perspectiva, 1979. p. 243-278.

ASSUNÇÃO, Ademir. Artilharia ligeira para um kamiquase. 2008. Disponível em: <http:// zonabranca.blog.uol.com.br/arch2008-08-17_2008-08-23.html>. Acesso em: 19 mar. 2009.

BAKHTIN, Mikhail. Problemas da poética de Dostoiévski. 2 ed. Trad. Paulo Bezerra. Rio de Janeiro: Forense, 1997.

BAKHTIN, Mikhail. A cultura popular na Idade Média e no Renascimento: o contexto de François Rabelais. Trad. Yara Frateschi Vieira. 4 ed. São Paulo: Hucitec; Brasília: Universidade de Brasília, 1999.

Bloom, Harold. A angústia da influência. Trad. Miguel Tamen. Lisboa: Cotovia, 1991.

BONVICINO, Régis (Org.). Envie meu dicionário: cartas e alguma crítica. São Paulo: Ed. 34, 1999.

BORGES, Jorge Luís. Kafka y sus precursores. In: Otras inquisiciones. Buenos Aires: Emecé Editores, 1960. p. 145-148.

CAMPOS, Haroldo de. Prólogo. In: LEMINSKI, Paulo. Caprichos e relaxos. São Paulo: Brasiliense, 1985. p. 9.

ECO, Umberto. Obra aberta: forma e indeterminação nas poéticas contemporâneas. 8 ed. Trad. Giovanni Cutolo. São Paulo: Perspectiva, 2001.

GADAMER, Hans-Georg. Verdade e método. 3 ed. Trad. Flávio Paulo Meurer. Petrópolis: Vozes, 1997.

GÓES, Fred; MARINS, Álvaro (Orgs.). Melhores poemas de Paulo Leminski. São Paulo: Global, 2001.

GUIMARÃES, Denise. Entrevista com Paulo Leminski. Nicolau, Curitiba, n. 19, ano III, 1989, p. 6-10.

KRISTEVA, Julia. Semiótica do romance. Lisboa: Arcádia, 1978.

LEMINSKI, Paulo. Agora é que são elas. 2 ed. São Paulo: Brasiliense; Curitiba: Fundação Cultural de Curitiba e Prefeitura da Cidade de Curitiba, 1984. $1^{\text {a }}$ reimpressão, 1999.

LEMINSKI, Paulo. Caprichos e relaxos. São Paulo: Brasiliense, 1985.

LEMINSKI, Paulo. Catatau. Curitiba: Edição do autor, 1975.

LEMINSKI, Paulo. Distraídos venceremos. 2 ed. São Paulo: Brasiliense, 1990.

LEMINSKI, Paulo. Ensaios e anseios crípticos. Alice Ruiz e Áurea Leminski (Introd. e org.). Curitiba: Pólo Editorial do Paraná, 1997.

LEMINSKI, Paulo. Gozo fabuloso. São Paulo: DBA, 2004.

LEMINSKI, Paulo. Guerra dentro da gente. São Paulo: Scipione, 1988.

LEMINSKI, Paulo. La vie en close. 5 ed. São Paulo: Brasiliense, 1991.

LEMINSKI, Paulo. Metaformose. São Paulo: Iluminuras, 1994.

LEMINSKI, Paulo. Não fosse isso e era menos / não fosse tanto e era quase. Curitiba: Ed. do Autor, 1980.

LEMINSKI, Paulo. O ex-estranho. Alice Ruiz e Áurea Leminski (Org.). São Paulo: Iluminuras, 1996. 
LEMINSKI, Paulo. Polonaises. Curitiba: Ed. do Autor, 1980.

LEMINSKI, Paulo. Quarenta clics em Curitiba. Jack Pires (fotos). 2 ed. Curitiba: Etcetera, 1990.

LEMINSKI, Paulo. Uma carta uma brasa através / Cartas a Régis Bonvicino (1976-1981). São Paulo: Iluminuras, 1992.

LEMINSKI, Paulo. Um escritor na biblioteca: Paulo Leminski. Curitiba: BPP/SECE, 1985.

LEMINSKI, Paulo. Vida: Cruz e Sousa, Bachô, Jesus e Trótski. Porto Alegre: Sulina, 1998.

LEMINSKI, Paulo. Winterverno. Suplicy Neto, João Virmond (ilustr.). Curitiba: Fundação Cultural de Curitiba, 1994.

MELLO, Cláudio J. de A. A intertextualidade pós-moderna de Agora é que são elas. Dissertação (Mestrado em Letras) - Faculdade de Ciências e Letras, Universidade Estadual Paulista. Assis, 2001

MELLO, Cláudio J. de A. Discurso social, história e política no romance histórico contemporâneo de língua portuguesa: Leminski, Lobo Antunes e Pepetela. Tese (Doutorado em Letras) - Faculdade de Ciências e Letras, Universidade Estadual Paulista. Assis, 2005.

MOREIRA, Paula Renata Melo. Espólio de Paulo Leminski: literatura contemporânea? Patrimônio cultural? In: Anais do IV ENECULT - Encontro de Estudos Multidisciplinares em Cultura, Salvador, UFBA, 2008. Disponível em: <http://www.cult.ufba.br/ enecult2008/14358.pdf>. Acesso em: 19 mar. 2013.

SALVINO, Rômulo Valle. Catatau: as meditações da incerteza. São Paulo: Educ, 2000.

SANTIAGO, Silviano. O entre-lugar do discurso latino-americano. In: Uma literatura nos trópicos: ensaios sobre dependência cultural. São Paulo: Perspectiva; Secretaria da Cultura, Ciência e Tecnologia do Estado de São Paulo, 1978. p. 11-28.

SARDUY, Severo. O barroco e o neobarroco. In: FERNÁNDEZ MORENO, César (Coord.). América Latina em sua literatura. Trad. Luiz João Gaio. São Paulo: Perspectiva, 1979. p. $161-178$.

TIEGHEM, Paul Van. Crítica literária, história literária, literatura comparada. In: COUTINHO, Eduardo; CARVALHAL, Tânia Franco (Orgs.). Literatura comparada: textos fundadores. Rio de Janeiro: Rocco, 1994. p. 89-96.

VAZ, Toninho. Paulo Leminski: o bandido que sabia latim. Rio de Janeiro: Record, 2001. 
